\title{
Vivian E. Strong (Ed) Gastric cancer: principles and practice
}

\author{
XVI, 333 p. 80 illus., 65 illus. in color. 2015, Springer, ISBN 978-3-319- \\ 15825-9 203, $29 €$ (D) | 208.99 € (A) | CHF 253.00. eBook available from \\ your library or springer.com/shop
}

\section{A. M. Prusa · S. F. Schoppmann}

Published online: 15 September 2015

(C) Springer-Verlag Wien 2015

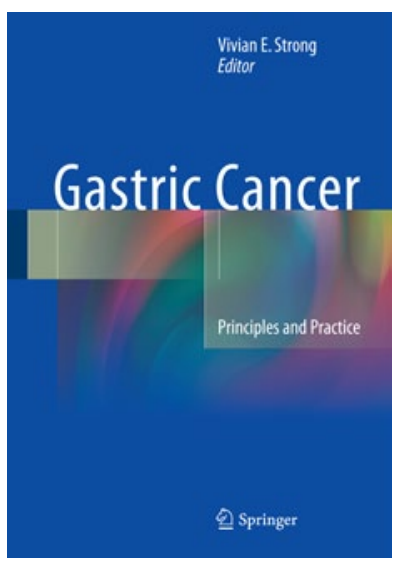

Although rates of death due to gastric cancer have been decreasing in many areas of the world in the past decades, gastric cancer is still among the five leading causes of cancer-related deaths in the world. Edited by Vivian E. Strong, "Gastric Cancer: Principles and Practice" provides a comprehensive and thorough review about the current status in gastric cancer management. Written by recognized authorities in the field, this book gives an excellent overview about the way how the topic is dealt with beginning more than 130 years ago with the pioneers of gastric surgery. The chapters contain in-depth and most current information including pathophysiology and molecular biology of gastric cancer. This volume also covers the entire field of modern diagnostic methods and tools including an algorithm for the workup process. A special emphasis to the role of staging laparoscopy and peritoneal cytology evaluation is given. In the "Gastric

Ao. Univ.-Prof. Dr. S. F. Schoppmann $(\bowtie)$.

Ass. Prof. Priv. Doz. Dr. A. M. Prusa

University Clinic for Surgery, Medical University Vienna,

Währinger Gürtel 18-20,

1090 Vienna, Austria

e-mail: sebastian.schoppmann@meduniwien.ac.at
Resection" chapter, a separate subsection devoted to minimal invasive endoscopic removal of early malignant lesions by performing EMR and ESD is provided. In addition, an excellent overview of surgical reconstruction methods following any form of gastric resection is presented and accompanied by a chapter dealing with the issue of the extent of lymphadenectomy. Two subsections especially corresponding to laparoscopic as well as robotic methods of resection and reconstruction for subtotal and total gastrectomy with D2 lymphadenectomy including high-quality images and illustrations are provided. In the final chapter, a detailed overview of neoadjuvant as well as adjuvant treatment concepts being confirmed on the basis of current research is presented. The different approaches to this topic depending on the geographical origin of gastric cancer treatment are taken into account as the underlying biology of East Asian gastric cancers is associated with better prognosis compared to western countries. In summary, "Gastric Cancer: Principles and Practice" by Strong et al. represents an exceptionally well structured reference for physicians delivering care to gastric cancer patients. It is a valuable tool not only for surgeons completing a surgical oncology fellowship but also for candidates preparing for certification or recertification in surgery.

\section{Conflict of interest}

The authors declare that there are no actual or potential conflicts of interest in relation to this article.

A. Prusa and S. F. Schoppmann, Medical University of Vienna 